\title{
BURNOUT DURING THE COVID PANDEMIC: A CASE OF THE SOCIAL SERVICES SECTOR IN LATVIA
}

\author{
iD Mareks Niklass ${ }^{1}$, Dr.sc.soc./ researcher
}

\author{
1 University of Latvia
}

\begin{abstract}
The paper analyses the results of an online survey of 443 social services sector employees carried out in October and November 2020 in Latvia. The survey was aimed to measure the impact of the pandemic on the social services sector, i.e. how social services were delivered, whether restrictions imposed have any effect on a given service (form, quality, quantity) as well as how social services sector organizations and employees coped with the pandemic both at organizational and psychological levels. A short version of the burnout measure developed by Ayala MalachPines was used to estimate the burnout level among social services sector employees. The survey results indicate that about one third of the surveyed employees are exposed to a high risk of burnout. Contrary to other studies, burnout has no relationship with the number of clients (a proxy variable for workload) served in a given institution. Burnout is more likely associated with factors related to the methodological, technical support and overall working conditions in one's organization.
\end{abstract}

Key words: burnout, social services sector, COVID pandemic.

JEL code: $\mathrm{I} 38$

\section{Introduction - the research problem and theoretical approach}

Israeli psychologist Ayala Malach-Pines views burnout as "a state of physical, emotional, and mental exhaustion" (Malach-Pines, A., 2005, p. 78). The understanding of burnout is a basis for the empirical analysis in this study. Burnout among social services sector employees is an acute problem identified in many countries (McFadden, P., Manthorpe, G. \& Mallett, J., 2018; Lizano, E. L. \& Barak, M. M., 2015; Holmes, M. et al., 2021; Kavaliauskiene, V., \& Balciunaite, R., 2015; Antonopoulou, P., Killian, M., \& Forrester, D., 2017; Valba, E., Toros, K., \& Tiko, A., 2017; Kim, B., Liu, L., Ishikawa, H., \& Park, S. H., 2019; Cohen-Serrins, J., 2021).

There have been a number of studies measuring burnout among social workers before the COVID pandemic. Most studies indicate that burnout among social workers is commonplace. They also provide a range of explanations for such a phenomenon. For example, the findings of a UK Burnout National Survey in 2015 conclude that: "Work-load has a major impact on well-being, feelings of working within or beyond capacity which seem likely to impact on the quality of service delivered" (McFadden, P., Manthorpe, G. \& Mallett, J., 2018, p. 1215). A survey of 193 social workers in child protection services in the UK reveals that about $20 \%$ of the surveyed reported elevated stress. This stress is linked to one's perceived work overload and role conflict as well as a lack of supervisor support and job autonomy (Antonopoulou, P., Killian, M., \& Forrester, D., 2017, pp. 48-49). Similar conclusions come from a systematic literature review on child protection social work where the authors confirm that "a major contributor to burnout is workload and staff being stretched beyond capacity" (McFadden, P., Campbell, A. \& Taylor, B., 2015, p. 1558).

A longitudinal study on public child welfare workers in Southern California suggests that "workplace experiences such as the level of support or training in the workplace influence burnout, which subsequently influences worker well-being" (Lizano, E. L. \& Barak, M. M., 2015, p. 26). A more recent survey carried out with 170 care workers at long-term care facilities in Hawai confirms that social support is negatively and significantly associated with burnout and there is a need to develop policies to reduce it (Kim, B., Liu, L., Ishikawa, H., \& Park, S. H., 2019, p. 57).

Drawing on semi-structured interviews with 26 child protection workers in Estonia, researchers found that one of the major barriers for a more successful family engagement in the context of assessment in

1 Tel.: +371259971880 E-mail address: mareks.niklass@lu.Iv 
child protection practice is high workload of employees that creates burnout (Valba, E., Toros, K., \& Tiko, A., 2017, p. 5 ). In their qualitative research study using structured interviews with social workers in child care homes and day care centres, Lithuanian scholars Kavaliauskiene and Balciunaite identified that: "the occupational burnout syndrome is more affected by the organisational (heavy workload, psychological discomfort at work, etc.) than by the individual factors" (Kavaliauskiene, V., \& Balciunaite, R., 2015, p. 35).

A very few studies have been so far carried on burnout among social workers in Latvia. They are mostly bachelor and master theses with small samples focusing on particular institutions (Leonenko, D., 2007; Rudzate, E., 2010; Zaharane, A., 2009). A notable exception is a study carried by Lana Barizikova (2020). Her master thesis was aimed to measure burnout levels among 120 social workers in larger cities in Latvia. She used the Maslach burnout inventory to identify the emotional exhaustion, personal achievement and depersonalization components of burnout. Most respondents in her study have average levels of burnouts in these three components (Barizikova, L., 2020, p. 45). Barizikova also finds that higher levels of burnout have no statistically significant relationship with one's caseload, length of service at a given organization and age. She also identifies that emotional exhaustion correlates with a higher job insecurity (Barizikova, L., 2020, p. 58)

There are only some studies published in peer reviewed journals measuring the effect of the COVID pandemic on the well-being of social workers. A recent study of 181 social workers in the US found that they experienced average levels of burnout. The study also stresses the need for organizational support to mitigate the effects of the pandemic on the wellbeing of staff members (Holmes, M. et al., 2021). CohenSerrins in his study on the impact of COVID-19 in the US social services sector noted that: "Social work in particular represents a profession where COVID-19 has magnified the initiates and impacts of occupational stress. Social workers operate on the macro-level navigating complex systems, advocating for underserved or underrepresented clients while also providing direct clinical interventions" (Cohen-Serrins, J., 2021, p. 259). In other words, the COVID pandemic is expected to magnify the existing problems and increase a risk of burnout among social workers.

This study is aimed to measure the burnout of social services sector employees in Latvia and thus contribute to the ongoing debate in academic literature how the COVID pandemic affects the social services sector and what accounts for higher levels of burnout among its employees. No study on such a scale has been carried out during the COVID pandemic in Latvia.

\section{Data and methodology}

This paper analyses the results of an online survey of 443 social services sector employees carried out in October and November 2020 in Latvia. 2409 e-mail addresses were obtained from various public sources (institutional websites, Register of Social Service Providers) to send an invitation letter to take part in the survey. The attained response level is $18.3 \%$, which is an average level. A recent article by Van Mol indicates that "a response rate below $10 \%$ is not uncommon for web surveys" and "web surveys generally get a 6 to $15 \%$ lower response rate compared to other survey modes" (Van Mol, C., 2017, p. 318).

The survey was aimed to measure the impact of the pandemic on the social services sector, i.e. how social services were delivered, whether restrictions imposed have any effect on a given service (form, quality, quantity) as well as how social services sector organizations and employees coped with the pandemic both at organizational and psychological levels. A short version of the burnout measure developed by Ayala Malach-Pines (Malach-Pines, A., 2005) was used to estimate the burnout level among social services sector employees. This tool requires little space on a questionnaire and little time for administration 
and analysis (Malach-Pines, A., 2005, p. 79). Its reliability and validity have been tested in a number of studies in different countries and cultures (Malach-Pines, A., 2005, p. 86).

The burnout measure includes 10 questionnaire items, for example, on how often a respondent feels tired, hopeless, depressed or disappointed with people at work. Respondents were asked to use a sevenpoint scale (from 1 indicating "never" to 7 - "always") to indicate their feelings about their job. The obtained burnout score is a simple arithmetic mean of the aforementioned 10 items. A score up to 2.4 indicates a very low level of burnout; 2.5 to 3.4 identifies danger signs of burnout; 3.5 to 4.4 - burnout; 4.5 to 5.4 a very serious problem of burnout. A score above 5.5 requires immediate professional help (Malach-Pines, A., 2005, p. 88).

\section{Empirical results}

To get a broader context of the survey and its results, Table 1 is included to provide detailed information about the makeup of the sample. A typical respondent was a 45-54 years old social worker with at least college degree. She (most social workers are women) has worked for more than 5 years at a given organization. More likely, it is a social service providing services and support for local people in smaller municipalities in Latvia. There are a very few social carers and supporting staff members in the sample, which is a shortcoming of this study. They are likely to be more exposed to the effects of the COVID pandemic (a close proximity to clients) and thus might have a higher burnout risk. The recruitment of the respondents via e-mails might account for such an outcome.

Table 1

Main characteristics of the sample

\begin{tabular}{|c|c|c|c|}
\hline $\begin{array}{l}\text { Socio-demographic } \\
\text { characteristics }\end{array}$ & $\%$ & Socio-demographic characteristics & $\%$ \\
\hline Age & & Seniority level & \\
\hline Up to 24 & 0.2 & Organizational manager/board member & 17.4 \\
\hline $25-34$ & 13.4 & Department/branch manager & 19.6 \\
\hline $35-44$ & 20.2 & Specialist/social worker/administrative clerk & 53.0 \\
\hline $45-54$ & 32.4 & Assistant/social carer/other supporting staff & 4.1 \\
\hline $55-64$ & 28.8 & Others & 2.1 \\
\hline $65+$ & 5 & Refusal to answer & 3.9 \\
\hline Educational level & & Type of organization & \\
\hline Less than college degree & 3.9 & Municipal institution/agency & 76.4 \\
\hline At least college degree & 62.5 & Non-governmental organization & 12.7 \\
\hline Master level degree & 33.6 & State institution/agency & 8.4 \\
\hline \multicolumn{4}{|l|}{$\begin{array}{l}\text { Length of service in the } \\
\text { organization }\end{array}$} \\
\hline Up to a year & 5.3 & Private sector operator/individual entrepreneur & 2.0 \\
\hline \multirow[t]{2}{*}{$1-2$} & & Place of service delivery* & \\
\hline & 10.3 & Riga & 25.5 \\
\hline $3-4$ & 15.8 & Republic cities & 19.5 \\
\hline $5+$ & 68.6 & Other municipalities & 61.2 \\
\hline
\end{tabular}

*Some organizations provide services in more than one municipality, $N=443$

Source: author's calculations based on an online survey of 443 social services sector employees in 2020 in Latvia 
The answers to the questionnaire items included in a short version of Ayala Malach-Pines' burnout measure are presented in Table 2. Most respondents sometimes or often feel tired or disappointed with people at work. A significant number of social services sector employees feel depressed and have difficulties sleeping. There are a few respondents who feel trapped and worthless at work. As pointed out above, the obtained burnout score is a simple arithmetic mean of the items presented in Table 2. A technical note. The answers of the respondents with missing responses are not included in the following calculations.

Table 2

\section{Questionnaire items measuring burnout among social services} sector employees (\%)

\begin{tabular}{|l|c|c|c|c|c|c|c|}
\hline \multicolumn{1}{|c|}{ Burnout indicators } & never & $\begin{array}{c}\text { almost } \\
\text { never }\end{array}$ & rarely & $\begin{array}{c}\text { someti } \\
\text { mes }\end{array}$ & often & $\begin{array}{c}\text { very } \\
\text { often }\end{array}$ & always \\
\hline Tired & 0.9 & 3.4 & 13.6 & 43.2 & 28.0 & 10.0 & 0.9 \\
\hline $\begin{array}{l}\text { Disappointed with } \\
\text { people }\end{array}$ & 5.0 & 8.7 & 24.1 & 41.3 & 16.1 & 4.8 & 0.0 \\
\hline Hopeless & 18.9 & 23.3 & 26.6 & 25.2 & 4.4 & 1.6 & 0.0 \\
\hline Trapped & 33.4 & 21.0 & 22.6 & 13.4 & 5.8 & 3.2 & 0.7 \\
\hline Helpless & 20.9 & 24.3 & 23.2 & 22.2 & 6.9 & 2.5 & 0.0 \\
\hline Depressed & 11.7 & 21.6 & 29.6 & 27.3 & 7.8 & 2.1 & 0.0 \\
\hline Physically weak/Sickly & 17.7 & 26.0 & 30.6 & 20.0 & 3.7 & 1.6 & 0.2 \\
\hline $\begin{array}{l}\text { Worthless/Like a } \\
\text { failure }\end{array}$ & 28.0 & 31.3 & 23.6 & 14.4 & 1.6 & 1.2 & 0.0 \\
\hline Difficulties sleeping & 12.3 & 21.8 & 24.4 & 27.1 & 9.3 & 3.7 & 1.4 \\
\hline "I've had it" & 19.1 & 22.8 & 18.7 & 26.3 & 7.8 & 5.1 & 0.2 \\
\hline
\end{tabular}

$n=422$

\section{Source: author's calculations based on an online survey of 443 social services sector employees in 2020} in Latvia

The survey data indicate that about one third of respondents experienced high levels of burnout (Table 3) as defined by Malach-Pines. Unexpectedly and somewhat surprisingly, the data analysis does not reveal that the burnout level is associated (no statistically significant relationship was found) with such factors as a number of clients served in a given organization, available funding and staff during the pandemic. Unfortunately, no follow up questions were asked about one's caseload (a number of clients to work directly with) that would be a more precise measure of one's workload. Furthermore, no significant relationship was found in regard to one's seniority level and a type of organization where he or she is employed. Similarly, one's age and length of service have no relationship with one's burnout level. 
Table 3

\section{Burnout levels among social services sector workers}

$n=422$

\begin{tabular}{|l|c|}
\hline \multicolumn{1}{|c|}{ Burnout level } & $\%$ \\
\hline a very low level of burnout & 29.6 \\
\hline danger signs of burnout & 38.6 \\
\hline burnout & 25.1 \\
\hline a very serious problem of burnout & 5.7 \\
\hline requires immediate professional help & 0.9 \\
\hline
\end{tabular}

Source: author's calculations based on an online survey of 443 social services sector employees in 2020 in Latvia

What factors can be associated with higher levels of burnout then? These are more likely to be what American psychologist Frederick Herzberg called hygiene factors in his two-factor theory (Alshmemri, M., Shahwan-Akl, L. \& Maude, P., 2017). Working conditions, supervision, organizational policies, administrative and technical support are those hygiene factors that are essential to get one's job done.

To make the following analysis more accessible, the author divided respondents in three categories by burnout levels, i.e. a group with low level of burnout (with the burnout score up to 2.4), those having danger signs of burnout (with the score between 2.5 and 3.4) and those with high levels of burnout (with the score above 3.5).

Respondents were asked to estimate the preparedness of their organization to tackle the pandemic, for example, whether they view organizational methodological/professional support as good, average or poor. Those with higher levels of burnout tend to look at training of employees, technical support, working time organization and methodological/professional support less favourably than others. In turn, those with low level of burnout are more likely to indicate that, for example, working time organization or working time planning at their organization were good during the pandemic (see Table 4). It should be noted though that these are self-assessments. No follow up questions were asked about concrete examples of preparedness. However, it is safe to argue that these answers at least partly reflect differences in how various organizations prepared for the pandemic. 
Organization's preparedness to tackle the pandemic by burnout levels (\%)

$* X 2(4, N=409)=14.2, p<.001$

\begin{tabular}{|l|c|c|c|}
\hline Characteristics of preparedness & good & average & poor \\
\hline \multicolumn{3}{|c|}{ Training of employees* } \\
\hline low level of burnout & 71.3 & 26.2 & 2.5 \\
\hline danger signs of burnout & 55.9 & 40.4 & 3.7 \\
\hline burnout & 48.4 & 46.0 & 5.6 \\
\hline
\end{tabular}

\begin{tabular}{|l|c|c|c|}
\hline \multicolumn{4}{|l|}{ Technical support** } \\
\hline low level of burnout & 66.1 & 32.2 & 1.7 \\
\hline danger signs of burnout & 51.6 & 42.2 & 6.2 \\
\hline burnout & 37.4 & 44.3 & 18.3 \\
\hline
\end{tabular}

Working Time Organization/Working Time Planning***

\begin{tabular}{|l|c|c|c|}
\hline low level of burnout & 81.2 & 15.4 & 3.4 \\
\hline danger signs of burnout & 62.7 & 31.1 & 6.2 \\
\hline burnout & 46.9 & 42.2 & 10.9 \\
\hline
\end{tabular}

Methodological/professional support****

\begin{tabular}{|l|l|l|l|}
\hline low level of burnout & 78.6 & 21.4 & 0.0 \\
\hline danger signs of burnout & 62.2 & 31.4 & 6.4 \\
\hline burnout & 52.0 & 41.5 & 6.5 \\
\hline
\end{tabular}

$* * X 2(4, N=410)=34.1, p<.001$

$* * * \times 2(4, N=406)=31.3, p<.001$

$* * * * X 2(4, N=396)=21.9, p<.001$

***** "hard to say" answers not included

Source: author's calculations based on an online survey of 443 social services sector employees in 2020 in Latvia

Work safety and job insecurity during the pandemic are also associated with one's burnout (Table 5). Those respondents who agreed with the statements such as "My workplace is equipped to ensure a sufficient distance between employees and the client" or "I have a separate room for working with the client" tend to have lower levels of burnout. They also tend to feel more secure in fulfilling their job responsibilities and less often feel afraid to get sick of COVID-19 after contact with their colleagues or clients. In contrast, those with high levels of burnout less often indicate that they have a sufficient distance between employees and the client and more often feel insecure. 
Work safety and the effect of the pandemic on one's work by burnout levels ( \%)

\begin{tabular}{|c|c|c|c|c|c|}
\hline $\begin{array}{c}\text { Questionnaire items by } \\
\text { burnout levels }\end{array}$ & Agree & $\begin{array}{l}\text { Rather } \\
\text { agree }\end{array}$ & $\begin{array}{l}\text { Rather } \\
\text { disagree }\end{array}$ & Disagree & $\begin{array}{c}\text { Chi-square/ } \\
\text { n/ p-value }\end{array}$ \\
\hline \multicolumn{6}{|c|}{ My workplace is equipped to ensure a sufficient distance between employees and the client } \\
\hline low level of burnout & 63.6 & 22.0 & 9.3 & 5.1 & 45.4 \\
\hline danger signs of burnout & 42.4 & 42.4 & 12.0 & 3.2 & 409 \\
\hline burnout & 34.6 & 27.8 & 22.6 & 15.0 & $<.001$ \\
\hline \multicolumn{6}{|c|}{ I have a separate room for working with the client } \\
\hline low level of burnout & 68.1 & 20.4 & 9.7 & 1.8 & 23.2 \\
\hline danger signs of burnout & 49.0 & 26.1 & 10.5 & 14.4 & 391 \\
\hline burnout & 45.6 & 24.0 & 11.2 & 19.2 & $<.001$ \\
\hline \multicolumn{6}{|c|}{ I feel less secure in fulfilling my job responsibilities } \\
\hline low level of burnout & 14.4 & 33.1 & 28.8 & 23.7 & 45 \\
\hline danger signs of burnout & 30.1 & 37.9 & 18.3 & 13.7 & 401 \\
\hline burnout & 44.6 & 39.2 & 10.8 & 5.4 & $<.001$ \\
\hline \multicolumn{6}{|c|}{ I'm afraid to get sick of COVID-19 after contact with the client } \\
\hline low level of burnout & 11.4 & 27.2 & 30.7 & 30.7 & 37.4 \\
\hline danger signs of burnout & 19.6 & 32.7 & 28.1 & 19.6 & 396 \\
\hline burnout & 33.3 & 35.7 & 25.6 & 5.4 & $<.001$ \\
\hline \multicolumn{6}{|c|}{ I am afraid to get sick of COVID-19 after contact with my colleague } \\
\hline low level of burnout & 12.8 & 23.9 & 32.5 & 30.8 & 24.3 \\
\hline danger signs of burnout & 14.2 & 33.5 & 29.0 & 23.2 & 402 \\
\hline burnout & 21.5 & 40.0 & 30.0 & 8.5 & $<.001$ \\
\hline \multicolumn{6}{|c|}{ I can protect myself from getting COVID-19 } \\
\hline low level of burnout & 24.2 & 49.2 & 23.3 & 3.3 & 28.3 \\
\hline danger signs of burnout & 19.9 & 39.7 & 34.0 & 6.4 & 403 \\
\hline burnout & 11.8 & 35.4 & 34.6 & 18.1 & $<.001$ \\
\hline
\end{tabular}

*Degree of freedoms - 6

**"hard to say" and "not applicable" answers not included

Source: author's calculations based on an online survey of 443 social services sector employees in 2020 in Latvia

It is hard to establish a causal link given the sample size (a small sample size limits the measurement of the effect and interplay of various factors) and a limited number of follow up questions included in the questionnaire but these results clearly identify a relationship between the so-called hygiene factors and burnout. Working conditions, organization and safety have a strong relationship with burnout. A safe and well-equipped workplace coupled with good management and professional support result in a lower level of burnout.

\section{Discussion}

This study indicates that one third of social services sector employees are experiencing high levels of burnout. Most respondents have average levels of burnout though, which is consistent with other studies elsewhere (Barizikova, L., 2020; Holmes, M. et al., 2021). 
Contrary to what other studies suggest (McFadden, P., Manthorpe, G. \& Mallett, J., 2018; McFadden, P., Campbell, A. \& Taylor, B., 2015; Kavaliauskiene, V., \& Balciunaite, R., 2015; Valba, E., Toros, K., \& Tiko, A., 2017), this study does not confirm that burnout is associated with one's workload. Questionnaire items indicating a number of clients served in one's organization and available staff during the pandemic have no relationship with one's burnout. It should be noted that the questionnaire used in the study do not include more precise questions about one's caseload and detailed characteristics of clients (age, sex, family status etc.). These questions might have given a more precise measurement of workload.

No significant relationship was found in regard to one's seniority level and a type of organization where a respondent is employed. Furthermore, one's age and length of service have no relationship with one's burnout level. Similar results have been obtained in Barizikova's study in 2020 in larger cities in Latvia (Barizikova, L., 2020).

This study confirms the results of some studies (Lizano, E. L. \& Barak, M. M., 2015; Kim, B., Liu, L., Ishikawa, H., \& Park, S. H., 2019) that support and training influences burnout. Those respondents that assessed the training of employees and professional support as good are more likely to have lower levels of burnout. In turn, poor training and support are more often linked with higher levels of burnout among employees.

At last, this study indicates that work safety and working conditions are closely linked to burnout during the COVID pandemic. Social services sector employees feel more secure and less exhausted in a wellequipped workplace where a sufficient distance between employees and the client is ensured. Higher levels of burnout are characteristic to those organizations where employees feel insecure and unprotected from the COVID. No study has been identified that confirms the aforementioned findings.

\section{Conclusions}

1) The author uses the burnout measure developed by Ayala Malach-Pines to estimate the burnout level among social services sector employees during the COVID pandemic in Latvia. No study on such a scale has been carried out so far.

2) The data obtained from an online survey of 443 social services sector employees in the autumn of 2020 indicate that about one third of respondents are exposed to a high risk of burnout. Most respondents are experiencing average levels of burnout, which is consistent with other studies.

3) Contrary to previous studies, this study does not confirm that burnout is associated with one's workload. No significant relationship was also found in regard to one's age and length of service, seniority level and a type of organization.

4) Good training, working time organization, professional and technical support are linked to a reduced risk of burnout. Employees that feel secure and protected are less likely to experience burnout. These aspects have been emphasized in other studies as well.

5) Overall, working conditions and safety are better predictors of burnout than other factors. Thus these findings are a valuable addition to academic debate and literature.

\section{Bibliography}

1. Alshmemri, M., Shahwan-Akl, L., \& Maude, P. (2017). Herzberg's Two-Factor Theory. Life Science Journal, Vol. 14(5), 12-16. DOI:10.7537/marslsj140517.03

2. Antonopoulou, P., Killian, M., \& Forrester, D. (2017). Levels of Stress and Anxiety in Child and Family Social Work: Workers' Perceptions of Organizational Structure, Professional Support and Workplace Opportunities in Children's Services in the UK. Children and Youth Services Review, Vol. 76, 42-50.

3. Barizikova, L. (2020). Burnout of Social Workers: Reasons and Solutions. Master Thesis. Sociology Department at the Faculty of Social Sciences, University of Latvia. 
4. Cohen-Serrins, J. (2021) How COVID-19 Exposed an Inadequate Approach to Burnout: Moving Beyond SelfCare In: Tosone C. (eds) Shared Trauma, Shared Resilience During a Pandemic. Essential Clinical Social Work Series. Springer, Cham. https://doi.org/10.1007/978-3-030-61442-3_26

5. Holmes, M.R., Rentrope, C.R., Korsch-Williams, A. et al. (2021). Impact of COVID-19 Pandemic on Posttraumatic Stress, Grief, Burnout, and Secondary Trauma of Social Workers in the United States. Clinical Social Work Journal. https://doi.org/10.1007/s10615-021-00795-y

6. Kavaliauskiene, V., \& Balciunaite, R. (2015). Profesinis perdegimas ir jo raiška socialinio darbo profesionalizacijos kontekste. Tiltai, 69(4), 17-36.

7. Kim, B., Liu, L., Ishikawa, H., \& Park, S. H. (2019). Relationships between Social Support, Job Autonomy, Job Satisfaction, and Burnout among Care Workers in Long-Term Care Facilities in Hawaii. Educational Gerontology, Vol. 45(1), 57-68.

8. Leonenko, D. (2007). Professional Burnout Syndrome as a Reason for Social Workers to Quit the Job. Diploma Work. Sociology Department at the Faculty of Social Sciences, University of Latvia.

9. Lizano, E.L., \& Barak,M.M. (2015). Job Burnout and Affective Wellbeing: a Longitudinal Study of Burnout and Job Satisfaction among Public Child Welfare Workers. Children and Youth Services Review, Vol. 55, 18-28.

10. Malach-Pines, A. (2005). The Burnout Measure, Short Version. International Journal of Stress Management, Vol. $12,78-88$.

11. McFadden, P., Campbell, A. \& Taylor, B. (2015). Resilience and Burnout in Child Protection Social Work: Individual and Organisational Themes from a Systematic Literature Review. The British Journal of Social Work, Vol. 45(5), 1546-1563.

12. McFadden, P., Manthorpe, G., \& Mallett, J. (2018). Commonalities and Differences in Social Work with Learning Disability and Child Protection: Findings from a UK 'Burnout' National Survey. The British Journal of Social Work, Vol. 48(5), 1199-1219.

13. Rudzate, E. (2010). Professional Burnout in Social Work and Its Prevention. Diploma Work. Sociology Department at the Faculty of Social Sciences, University of Latvia.

14. Valba, E., Toros, K., \& Tiko, A. (2017). Family Engagement within the Context of Assessment in Child Protection Practice: The Case of Estonia. Child \& Family Social Work, Vol. 22(4), 1506-1514.

15. Van Mol, C. (2017) Improving Web Survey Efficiency: the Impact of an Extra Reminder and Reminder Content on Web Survey Response, International Journal of Social Research Methodology, Vol. 20:4, 317-327, DOI: $10.1080 / 13645579.2016 .1185255$

16. Zaharane, A. (2009). Risk Factors of Professional Burnout among Social Carers. Diploma work. Sociology Department at the Faculty of Social Sciences, University of Latvia. 